Journal Homepage: $-\underline{w w}$.journalijar.com
ISSN NO. 2320-5407

RESEARCH ARTICLE

\title{
STUDY OF ENDOTHELIAL DYSFUNCTION IN TYPE 1 DIABETES MELLITUS USING DOPPLER ULTRASOUND.
}

\author{
Dr. Hemant Mahur ${ }^{1}$, Dr. Ayush Jain ${ }^{2}$, Dr. D.P. Singh ${ }^{3}$, Dr. Jerin Romeo ${ }^{4}$, Dr. Chandraprakash Mudgal ${ }^{2}$ and \\ Dr. Chinmay Hegde ${ }^{2}$. \\ 1. Professor, Department of Medicine R.N.T. Medical College, Udaipur, Rajasthan(India). \\ 2. Post-Graduate Resident, Department of Medicine R.N.T. Medical College, Udaipur, Rajasthan(India). \\ 3. Sr. Professor, Department of Medicine R.N.T. Medical College, Udaipur, Rajasthan(India). \\ 4. Sr. Resident,Department of Medicine R.N.T. Medical College, Udaipur, Rajasthan(India).
}

\section{Manuscript Info}

Manuscript History

Received: 12 March 2019

Final Accepted: 14 April 2019

Published: May 2019

\section{Abstract}

Introduction:Microvascular diabetic complications are the most common causes of morbidity and mortality in patients with type $1 \mathrm{DM}$. The main etiology for mortality and a great percent of morbidity in patients with diabetes mellitus is atherosclerosis. A hypothesis for the initial lesion of atherosclerosis is endothelial dysfunction

Aim:This study aims to evaluate the incidence of endothelial dysfunction in type $1 \mathrm{DM}$ in relation to glycaemic control, duration of disease and other factors using Doppler ultrasound.

Methods:A prospective case control study was conducted on 50 type 1 DM cases and 50 matched controls over a period of one year from January 2018 to December 2018 using colour doppler ultrasonography of brachial artery.

Results:It was observed that among the 50 type $1 \mathrm{DM}$, endothelial dysfunction was (FMD<10\%) present among $19(38 \%)$ cases and 1 (2\%) controls. Macroalbuminuria as measured by urine ACR was present in 3 cases $(6 \%)$ of type1 DM while none of the controls had macroalbuminuria. Microalbuminuria was present in 13 cases $(26 \%)$ and 4 controls (8\%). Diabetic Retinopathy was noted in 7 cases of Type $1 \mathrm{DM}(14 \%)$ and all of them had endothelial dysfunction.

Conclusion:Endothelial dysfunction was seen in all duration of diabetes $(<5,5-10,>10$ years $)$ and prevalence increased with duration of diabetes. Identification of endothelial dysfunction early in the course of Type 1 DM, it may be possible to delay the development of microvascular and macrovascular complications, ultimately reducing the morbidity of the disease.

Copy Right, IJAR, 2019,. All rights reserved.

\section{Introduction:-}

Diabetes Mellitus (DM) is defined as a disturbance of intermediary metabolism manifesting as chronic sustained hyperglycemia primarily due to either an absolute or a relative lack of insulin. There are two broad categories of DM, designated as type 1 and type 2. Type $1 \mathrm{DM}$ is the result of interactions of genetic, environmental, and

Corresponding Author:-Dr. Ayush Jain.

Address:-Post-graduate Resident, Department of Medicine R.N.T. Medical College, Udaipur, 
immunologic factors that ultimately lead to the destruction of the pancreatic beta cells and insulin deficiency. Type 1 DM, which can develop at any age, develops most commonly before 20 years of age. Worldwide, the incidence of type $1 \mathrm{DM}$ is increasing at the rate of $3-4 \%$ per year for uncertain reasons ${ }^{1}$.

Diabetes related complications affect many organ systems and are responsible for the majority of morbidity and mortality associated with the disease ${ }^{2}$. Microvascular diabetic complications are the most common causes of morbidity and mortality of patients with type 1 disease. Diabetic nephropathy is becoming the single most common cause of end stage renal failure, while diabetic retinopathy is the most common cause of blindness in working-age population $^{3}$.

The main etiology for mortality and a great percent of morbidity in patients with diabetes mellitus is atherosclerosis ${ }^{4}$. Endothelial function is thought to be an important factor in the pathogenesis of atherosclerosis. In the 1990s, high-frequency ultrasonographic imaging of the brachial artery to assess endothelium-dependent flowmediated vasodilation (FMD) was developed. The technique provokes the release of nitric oxide, resulting in vasodilation that can be quantitated as an index of vasomotor function. The noninvasive nature of the technique allows repeated measurements over time to study the effectiveness of various interventions that may affect vascular health. The capacity of blood vessels to respond to physical and

chemical stimuli in the lumen confers the ability to self regulate tone and to adjust blood flow and distribution in response to changes in the local environment. Many blood vessels respond to an increase in flow, or more precisely shear stress, by dilating. This phenomenon is designated as FMD. A principal mediator of FMD is endothelium derived nitric oxide $(\mathrm{NO})^{5}$.

\section{Materials and Methods:-}

After approval from the institutional ethical committee and written well informed consent from patient, the prospective case control study was performed at R.N.T Medical College and associated group of hospitals, Udaipur (Rajasthan) on 50 type 1 diabetes patients and 50 age and sex matched controls(who satisfied exclusion criteria) from January 2018 to December 2018.

\section{Inclusion Criteria}

Type 1 diabetes patients

\section{Exclusion Criteria}

1. Obesity -Body mass Index $(\mathrm{BMI})>30 \mathrm{~kg} / \mathrm{m} 2$

2. Arterial hypertension

3. Any underlying disease other than diabetes

4. Use of Angiotensin Converting Enzyme (ACE) inhibitors/ Angiotensin receptor blockers

5. Proven Clinical atherosclerosis

6. Diabetes mellitus Type 2

Basic anthropometric measurements and biochemical test such as fasting blood sugar (FBS), Postprandial Blood sugar (PPBS), Glycosylated Haemoglobin (HbA1C), Fasting lipid profile (FLP), Morning urine spot sample albumin creatinine ratio (ACR) were obtained from all study subjects.

Endothelial function was assessed non invasively using colour doppler ultrasonography of brachial artery , using Siemens Acuson S3000 ultrasonography system with $10 \mathrm{MHz}$ linear probe by Flow mediated vasodilatation (FMD) after overnight fasting ${ }^{6}$.

FMD is calculated as-

FMD $=(\mathrm{d} 3-\mathrm{d} 1) \times 100 / \mathrm{d} 1$; where $\mathrm{d} 3$ is brachial artery diameter at 1 minute sphygmomanometer cuff release and $\mathrm{d} 1$ is the baseline diameter of brachial artery before occlusion with cuff.

FMD $<10 \%$ is taken as significant endothelial dysfunction ${ }^{10}$.

The flow in the brachial artery was calculated as

Baseline flow $=\pi \mathrm{d} 12 / 4$. HR1. (VTIS1 + VTId1);

Where $\mathrm{d} 1$ is brachial artery diameter, HR1 is heart rate, VTI S1 is systolic VTI and VTID1 is diastolic VTI at baseline. 
Reactive hyperemia flow $=\pi \mathrm{d} 22 / 4$.HR2 (VTIS2 + VTID2);

Where $\mathrm{d} 2$ is brachial artery diameter, HR2 is heart fate, VTIS2 is systolic VTI and VTID2 is diastolic VTI measured immediately after release of cuff.

Percentage increase in brachial artery flow was calculated as-

$\%$ Reactive hyperemia $=($ Reactive hyperemia flow- baseline flow $) \times 100 /$ Baseline flow

\section{Plan For Data Analysis}

At the end of the study, the data was compiled, tabulated and analysed for variation of means and correlation by appropriate biomedical software. The SPSS for the windows ver.16.00 statistical package program was used in the evaluation of the data. Appropriate test of significance was applied i.e. Chi-square test for qualitative data and Student ' $t$ ' test was applied for quantitative data. $p$ value less than 0.05 was considered significant.

\section{Results:-}

A total number of 100 subjects, with 50 patients diagnosed as cases of DM type 1 and, 50 age and sex matched controls were selected, keeping in norms to the inclusion and exclusion criteria. Out of the total 50 patients who were enrolled in the study, 22 were males and 28 were females, with the age ranging from 9-45 years. The distribution was same among the controls. The duration of the DM type 1 in patients range from 0-14 years.

The endothelial dysfunction was measured in all study subjects using Doppler ultrasound by standardized protocols. It was found that the mean endothelial function as assessed by FMD among DM type 1 patients was significantly lower than in controls. Of the 50 patients of DM type 1 studied, 19 patients had significant endothelial dysfunction $($ FMD $<10 \%)$ (Table-1). Only 1 in 50 controls was found to have significant endothelial dysfunction .Further it was observed that the endothelial dysfunction is positively correlated with increasing age, duration of diabetes and abnormal lipid profile(Table-2).

Table 1:-Comparison Of Measured Parameters Of Fmd Assessment In Study Groups

\begin{tabular}{|c|c|c|c|c|c|c|c|c|}
\hline Study Variables & $\begin{array}{l}\text { Study } \\
\text { Group }\end{array}$ & $\begin{array}{l}\text { No of } \\
\text { subjects }\end{array}$ & Mean & $\begin{array}{l}\text { Std. } \\
\text { Deviation }\end{array}$ & $\begin{array}{l}\text { Std. } \\
\text { Error } \\
\text { Mean }\end{array}$ & t-value & df & p-value \\
\hline \multirow{2}{*}{$\begin{array}{l}\text { Baseline } \\
\text { diameter(d1) }\end{array}$} & Cases & 50 & 3.37 & 0.869 & \multirow{2}{*}{0.452} & \multirow{2}{*}{2.72} & \multirow{2}{*}{98} & \multirow{2}{*}{0.008} \\
\hline & Controls & 50 & 2.91 & 0.790 & & & & \\
\hline \multirow[t]{2}{*}{$\begin{array}{l}\text { Diameter After } \\
\text { reactive } \\
\text { Hyperemia (d3) }\end{array}$} & Cases & 50 & 3.71 & 0.865 & \multirow[t]{2}{*}{0.463} & & \multirow[t]{2}{*}{98} & \multirow[t]{2}{*}{0.007} \\
\hline & Controls & 50 & 3.25 & 0.821 & & & & \\
\hline \multirow[t]{2}{*}{ FMD $\%$} & Cases & 50 & 11.052 & 3.40 & \multirow{2}{*}{0.578} & & \multirow{2}{*}{98} & \multirow{2}{*}{0.037} \\
\hline & Controls & 50 & 14.874 & 2.53 & & & & \\
\hline
\end{tabular}

Significant at $\mathrm{p}$ - value $<.05$

Table 2:-Association Of Fmd With Risk Factors In Type 1 Diabetes

\begin{tabular}{|l|l|l|l|}
\hline Risk Factors & FMD $<\mathbf{1 0 \%}(\mathbf{n}=\mathbf{1 9})$ & FMD $\geq \mathbf{1 0 \%}(\mathbf{n}=\mathbf{3 1})$ & Significance By P value \\
\hline Age in years & $33 \pm 8.9$ & $17 \pm 6.2$ & 0.001 \\
\hline BMI & $21.2 \pm 2.64$ & $17.7 \pm 3.26$ & 0.001 \\
\hline WHR & $0.8 \pm .02$ & $0.78 \pm .03$ & 0.001 \\
\hline HbA1C & $9.7 \pm 1.4$ & $9.8 \pm 1.8$ & 0.003 \\
\hline Urine ACR & $7.36 \pm 12.8$ & $1.55 \pm .42$ & 0.001 \\
\hline Age at diagnosis & $24.7 \pm 5.0$ & $16.0 \pm 5.1$ & 0.004 \\
\hline Duration of disease & $8.2 \pm 4.8$ & $1.7 \pm 1.7$ & 0.001 \\
\hline
\end{tabular}




\section{Discussion:-}

Endothelial dysfunction is a key early event in atherogenesis and is known to appear long before the formation of structural atherosclerotic changes. Assessment of endothelial function thus can provide valuable insight into preintrusive phase of atherosclerotic disease.

In this study, among the 50 cases of type1 DM 22 were male (44\%) and 28 were females (58\%). The sex distribution of this study is comparing to study by R Hurks et al in which males were $12(46 \%)$ and females were $14(58 \%){ }^{11}$.

The mean age among the type 1 diabetes is $23.56 \pm 10.49$ years and controls was $22.86 \pm 8.74$ years. $R$ Hurks et al in their study the mean age of Type 1 diabetes was $22.1 \pm 2.0$ and that of controls were $21.1 \pm 1.7$, which is comparable but lower than the present study ${ }^{11}$.

In this study the mean BMI of type 1 diabetes is $19.07 \pm 3.4$ and of controls is $21.46 \pm 2.2 \mathrm{~kg} / \mathrm{m} 2$ with $\mathrm{p}$ value $<0.001$. Ravikumar et al in their studies observed that BMI in diabetic was (24.8 \pm 4.0$)$ and in control (23.9 \pm 3.7$) \mathrm{p}$ value $<2.236$. However, Good fellow J, Ramsay et al, in their study the mean BMI was 26.9. In the present study BMI is significantly reduced compared to other studies ${ }^{12}$.

In this study it is noted the mean baseline diameter of brachial artery in cases is $3.37 \pm 0.869$ and $2.91 \pm 0.79$ in controls. However study done by Bhargava $\mathrm{K}$ et al the mean baseline diameter in diabetes was $3.773 \pm 0.729$, there was no significant difference between the studies ${ }^{13}$. Good fellow, Ramsay et al, in their study the cases had a mean baseline diameter of $4.82 \pm 0.6$ and controls $4.47 \pm 1.05$, which is higher to the present study ${ }^{12}$.

In this study, it is noticed that the mean FMD\% in type $1 \mathrm{DM}$ is $11.05 \pm 3.4$ and among the controls is $14.87 \pm 2.53 ; \mathrm{p}$ value 0.037 . FMD \% was significantly reduced in diabetes compared to controls. However, in the study by R Hurks, MJ Eisinger et al the FMD\% in type $1 \mathrm{DM}$ was found to be $7.13 \pm 0.43$ and that in control was $8.77 \pm 0.43$ (p value $<.002)$; which much lower compared to the present study ${ }^{11}$. Lekakis et al in their FMD\% in type 1 DM cases was found to be $5.8 \pm .7$ and controls it was $11 \pm 0.7(\mathrm{p}=0.01)$ also shown that FMD\% was significantly lower in type 1 $\mathrm{DM}^{14}$. Clarkson et al in their study showed FMD to be significantly impaired in diabetes as compared to controls $(5.0 \pm 3.7 \% \text { vs. } 9.3 \pm 3.8 \% ; p<0.001)^{15}$. In the study by Dogra G, Rich L et al the mean FMD\% in diabetic patient was $5.9 \pm 0.6$ and in controls was $7.9 \pm 0.6$; $\mathrm{p}$ value $<0.001^{16}$. Bhargava $\mathrm{K}$ et al, in their study observed that the mean FMD $\%$ in diabetes was $5.506 \pm 2.12$ and in controls was $9.6 \pm 1.8 ; \mathrm{p}$ value $<0.003^{13}$. In the present study and previous studies, FMD\% is significantly reduced in diabetes compared to controls.

\section{Conclusion:-}

In this study, out of the 50 cases of type 1 DM endothelial dysfunction was present in 19 (38\%) cases. Endothelial dysfunction was seen in all duration of diabetes $(<5,5-10,>10$ years) and prevalence increased with duration of diabetes. Out of 50 patients of type 1 DM, 3 (6.0\%) patients had macroalbuminuria and all of them had endothelial dysfunction. Diabetic retinopathy was present in $7(14.0 \%)$ cases of type $1 \mathrm{DM}$ and all of them found to have endothelial dysfunction.

By identification of endothelial dysfunction early in the course of Type 1 DM, it may be possible to delay the development of microvascular and macrovascular complications, ultimately reducing the morbidity of the disease. Hence methods to determine endothelial dysfunction early in the course of disease should be studied in detail in order to identify the complications of the disease and reduce the morbidity and mortality associated with it.

\section{References:-}

1. Harrisons principles of clinical medicine $-19^{\text {th }}$ edition, Chapter 417, P.2403.

2. Robert E Ratner. The Imperative to Prevent Diabetes Diabetes Care 2012 Dec; 35(12): 2417-2418

3. Kulenovic I, Rasic S, Karcic S. Development of microvascular complications in type 1 diabetic patients 10 years follow-up. Bosn J Basic Med Sci. 2006 May;6(2):47-50.

4. Anderson TJ, Gerhard MD, Meredith IT, Charbonneau F, Delagrange D, Creager MA, Selwyn AP, Ganz P. Systemic nature of endothelial dysfunction in atherosclerosis. Am J Cardiol. 1995;75:71B-74B.

5. Corretti MC, Anderson TJ, Benjamin EJ, Celermajer D, Charbonneau F, Creager MA, Deanfield J, Drexler H, Gehard-Herman M, Herrington D, Vallance P, Vita J, Vogel R. Guidelines for the ultrasound assessment of endothelial-dependent flow-mediated vasodilation of the brachial artery. J Am Coll Cardiol. 2002; 39: 257-265 
6. Celermajer DS, Sorensen KE, Gooch VM, Spiegelhalter DJ, Miller OI, Sulliva ID, Llyod JK, Jeanfield JE. Noninvasive detection of endothelial dysfunction in children and adults at risk of atherosclerosis .The Lancet 1992; 340(8828):1111-1115.

7. Jadhav UM, Sivaramakrishanan A, Kadam NN. Non-invasive assessments of endothelial dysfunction by brachial artery flow mediated dilatation in prediction of coronary artery disease in Indian Subjects. Indian Heart J 2003; 55: 44-48.

8. Stehouwer CDA, Nauta JJP, Zeldenrust GC, Hackeng WHL, Donker AJM, Den Ottolander GJ. Urinary albumin excretion, cardiovascular disease, and endothelial dysfunction in non-insulin-dependent diabetes mellitus. Lancet 1992; 340: 319-23.

9. Neunteufl T, Heher S, Katzenschlager R, Hassan A. Late prognostic value of flow-mediated dilation in the brachial artery of patients with chest pain. Am J Cardiol 2000; 86,207-2104

10. Dipti Chand, Kamble BG, Chand AG, Fuse SM, Ambhore NN. Endothelial function in Type 2 diabetic subjects compared with healthy controls. JAPI 2001;49: 74-5

11. R Hurks, M J Eisinger, I Goovaerts, L van Gaal, C Vrints, J Weyler, J Hendriks, P van Schil,P Lauwers .Early Endothelial Dysfunction in Young Type 1 Diabetics Eur J Vasc Endovasc Surg.2009 May;37(5):611-5.

12. Goodfellow J, Ramsey MW, Luddington LA, Jones CJH, Coates PA, Dunstan F. Endothelium and inelastic arteries: An early marker vascular dysfunction in non-dependent diabetes. BMJ 1996; 312: 744-745.

13. Bhargava K, Hansa G, Bansal M, Tandon S, Kasliwal RR. Endothelium dependent brachial artery mediated vasodilation in patients with diabetes mellitus and without coronary artery disease. JAPI 2003; 51: 355-358.

14. John Lekakis ,Christos Papamichael, Helen Anastasiou, Maria Alevizaki, Nicos Desses, Athan Souvatzoglou, Stamatios Stamatelopoulos, Demetrios A Koutras Endothelial dysfunction of conduit arteries in insulindependent diabetes mellitus without microalbuminuria . Cardiovasc Res (1997) 34 (1): 164-168.

15. Clarkson P, Celermajer DS, Donald AE, Sampson M, Sorensen KE, Adams M, Yue DK, Betteridge DJ, Deanfield JE. Impaired vascular reactivity in insulin-dependent diabetes cholesterol levels. J Am Coll Cardiol. 1996 Sep; 28(3):573-9

16. Dogra G, Rich L, Stanton K, Watts GF. Endothelium-dependent and independent vasodilation studies at normoglycemia in type I diabetes mellitus with and without microalbuminuria. Diabetologia 2001; 44(5): 593601. 